\title{
Pyridine and thiazole based hydrazides with promising anti-inflammatory and antimicrobial activities along with their in silico studies
}

Vinuta Kamat ${ }^{\mathrm{a}}$, Rangappa Santosh ${ }^{\mathrm{a}}$, Boja Poojary ${ }^{\mathrm{a}}$, Suresh P. Nayak ${ }^{\mathrm{a}}$, Banoth Karan

Kumar $^{\mathrm{b}}$, Murugesan Sankaranarayanan ${ }^{\mathrm{b}}$, Faheem $^{\mathrm{b}}$, Sheela Khanapure ${ }^{\mathrm{c}}$, Delicia Avilla

Barretto $^{c}$, Shyam K. Vootla ${ }^{c}$

${ }^{a}$ Department of Post-Graduate Studies \& Research in Chemistry, Mangalore University, Mangalagangothri-574199, Dakshina Kannada, Karnataka, India.

Tel.: +91-824-2287262(O); fax: +91-824-2287367/2287424.

${ }^{b}$ Medicinal Chemistry Research Laboratory, Department of Pharmacy, Birla Institute of Technology and Science, Pilani, Pilani Campus, Rajasthan-333031, India.

${ }^{c}$ Department of Biotechnology and Microbiology, Karnataka University, Dharwad-580003, Karnataka, India.

*Author for correspondence: bojapoojary@ gmail.com

\section{Table of content}

\section{Spectral data}

1.1. IR spectra of $\mathbf{5 b}, \mathbf{5 d}$ and $\mathbf{5 h}$ - Figure $\mathrm{S} 1-3$.

1.2. ${ }^{1} \mathrm{H}$ NMR spectra 5a, and $\mathbf{5 b}$ - Figure $\mathrm{S} 4,5$.

1.3. ${ }^{13} \mathrm{C}$ NMR spectra of $\mathbf{5 a}$, and $\mathbf{5 b}$ - Figure $\mathrm{S} 6,7$.

1.4. ES-MS spectra of compounds $\mathbf{5 b}, \mathbf{5 d}$ and $\mathbf{5 h}$ - Figure S8 - 10.

\section{Figures S11-S12}

Figures S11-S12 are graphical representations of results of the antibacterial and antifungal evaluation of the compounds. 


\section{Spectral data}

1.1. IR spectra of compounds $5 \mathrm{~b}, 5 \mathrm{~d}$ and $5 \mathrm{~h}$.

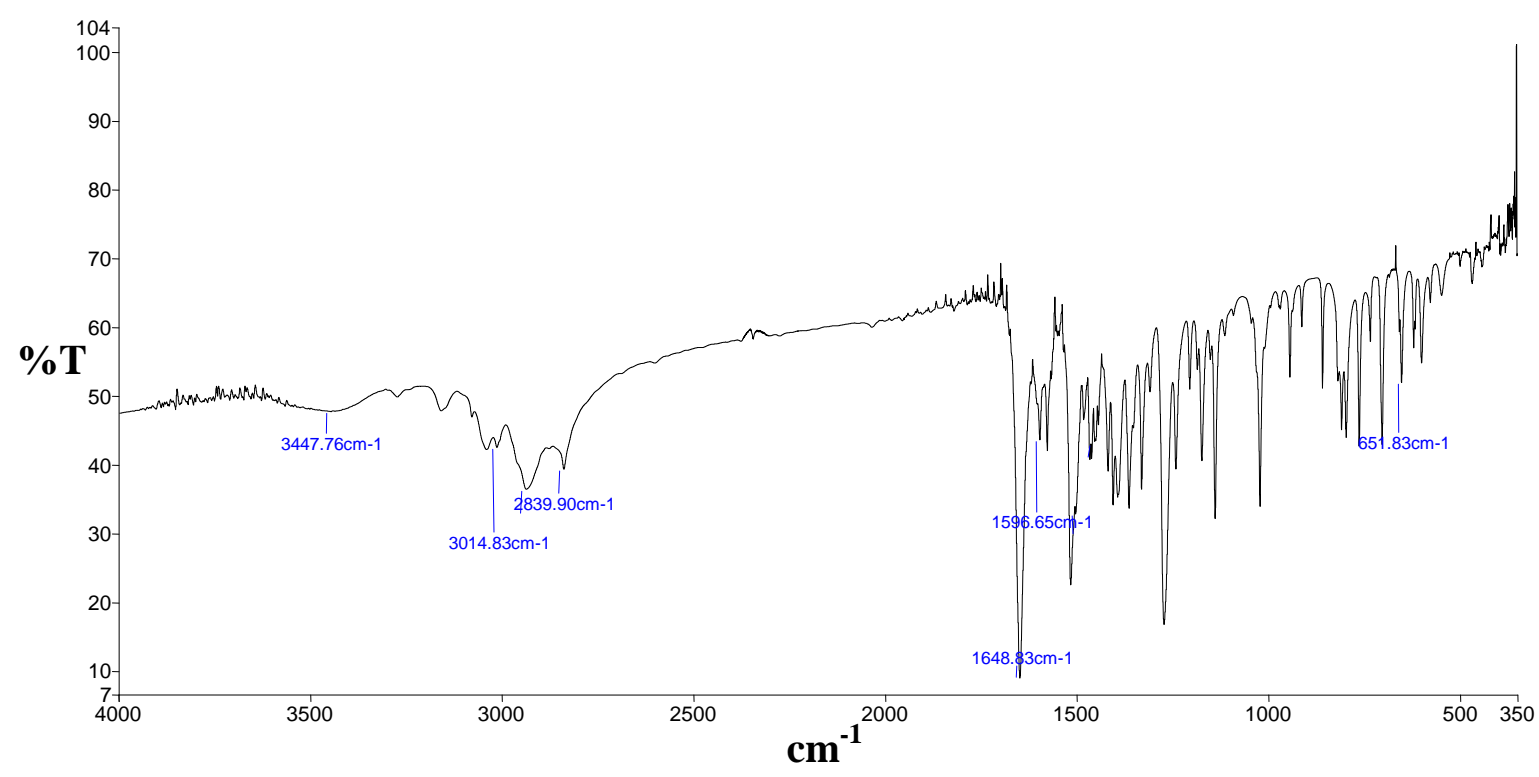

Figure S1. IR Spectrum of $N^{\prime}$-(3,4-dimethoxybenzylidene)-5-methyl-2-(pyridin-3yl)thiazole-4-carbohydrazide (5b). 


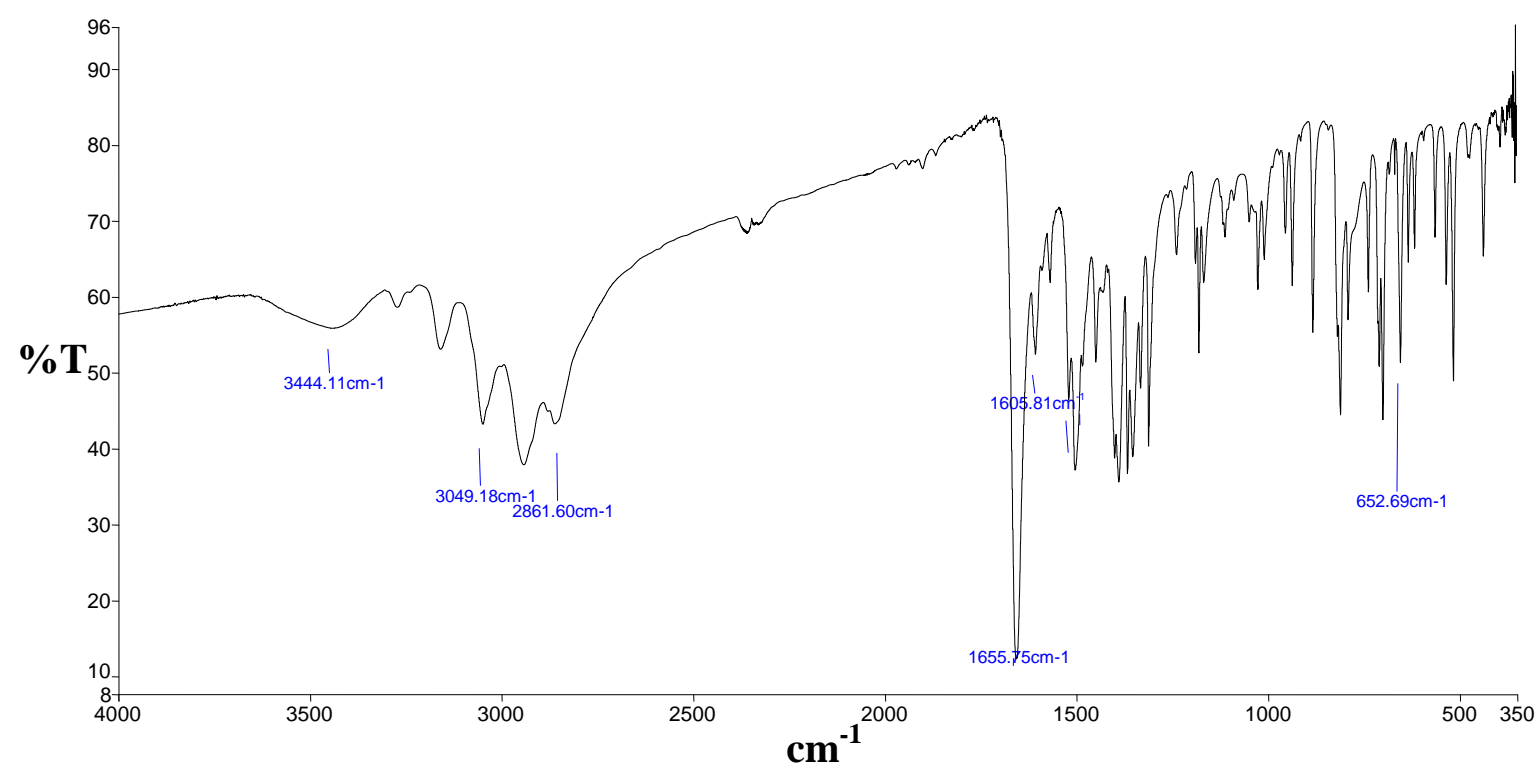

Figure S2. IR Spectrum of 5-Methyl- $N^{\prime}$-(4-methylbenzylidene)-2-(pyridin-3-yl)thiazole-4carbohydrazide (5d). 


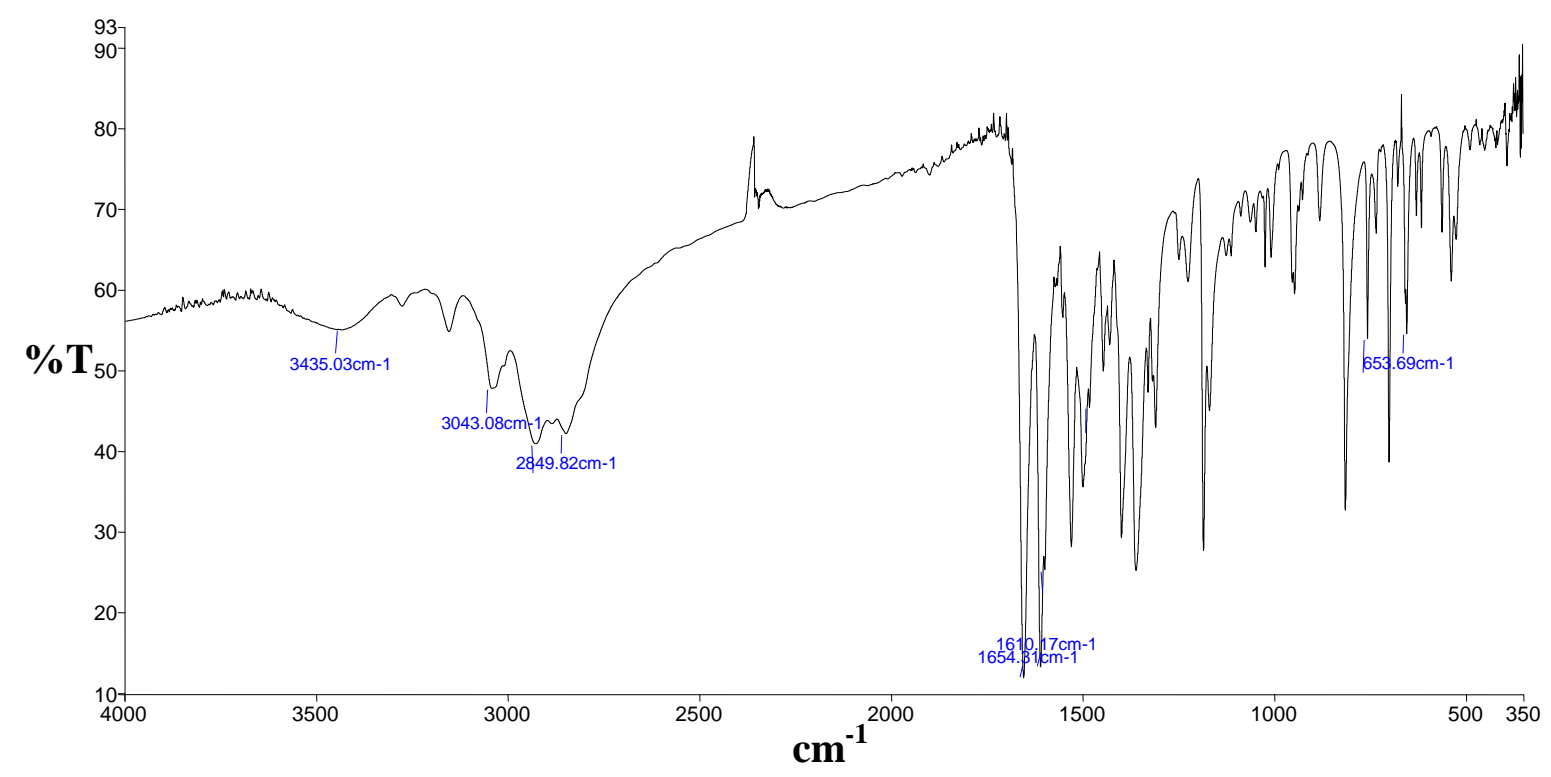

Figure S3. IR Spectrum of $N^{\prime}$-(4-dimethylaminobenzylidene)-5-methyl-2-(pyridine-3yl)thiazole-4-carbohydrazide (5h). 
1.2. ${ }^{1} \mathrm{H}$ NMR spectra of compounds $5 \mathrm{a}$ and $5 \mathrm{~b}$.

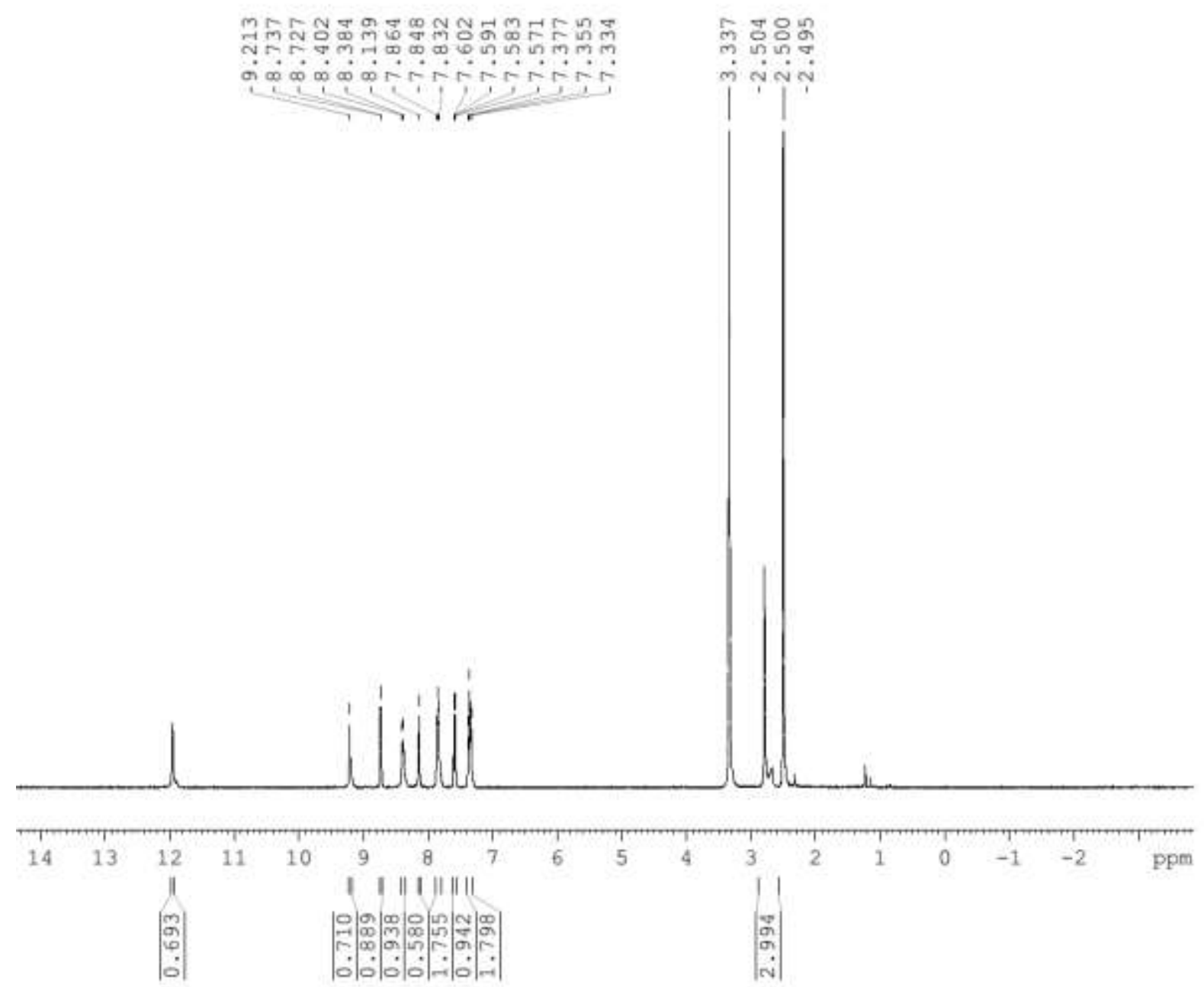

Figure S4. ${ }^{1} H$ NMR spectrum of $N^{\prime}$-(4-chlorobenzylidene)-5-methyl-2-(pyridin-3yl)thiazole-4-carbohydrazide (5a). 


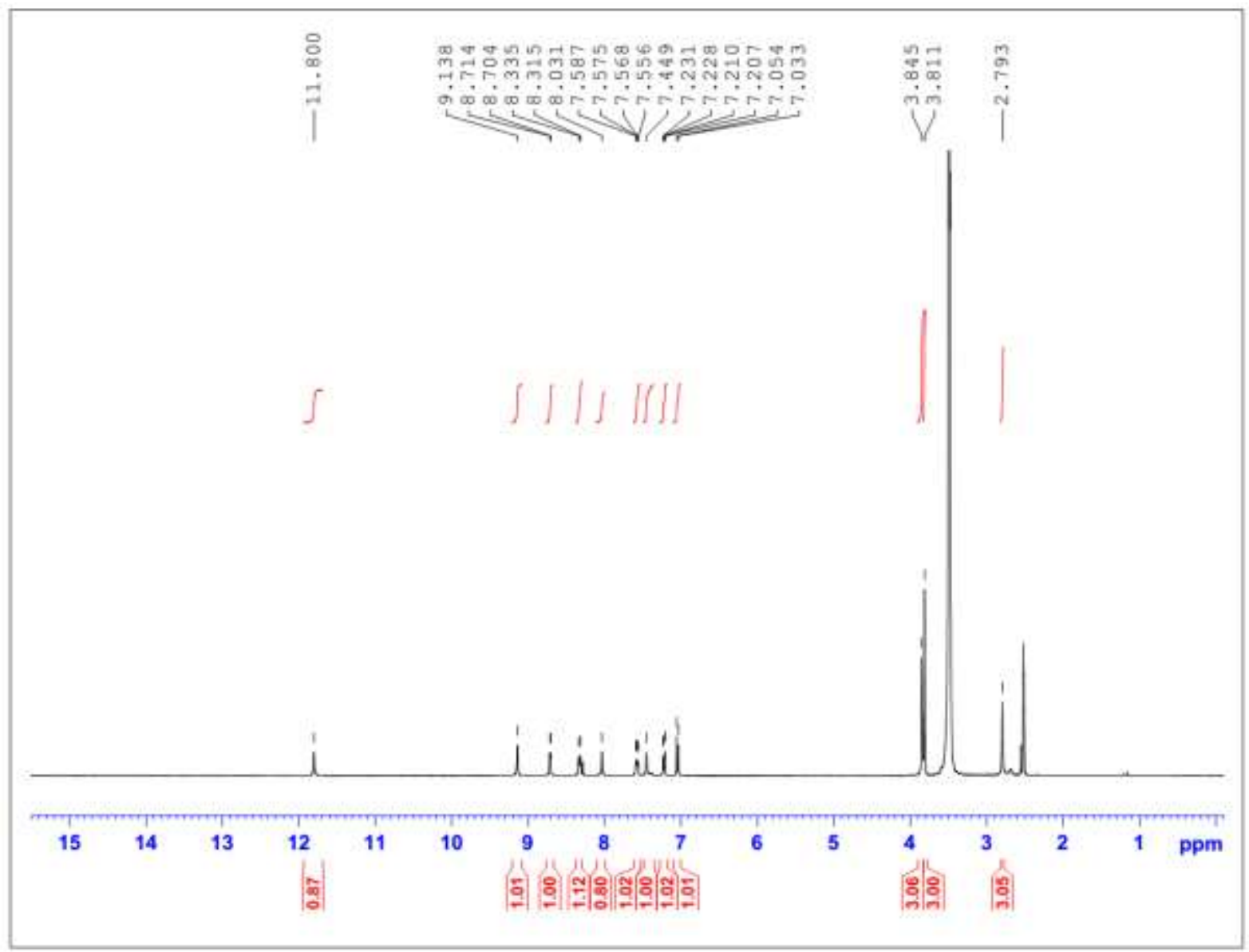

Figure S5. ${ }^{1} H$ NMR spectrum of $N^{\prime}$-(3,4-dimethoxybenzylidene)-5-methyl-2-(pyridin-3yl)thiazole-4-carbohydrazide (5b). 
1.3. ${ }^{1} \mathrm{C}$ NMR spectra of compounds $5 \mathrm{a}$ and $5 \mathrm{~b}$.
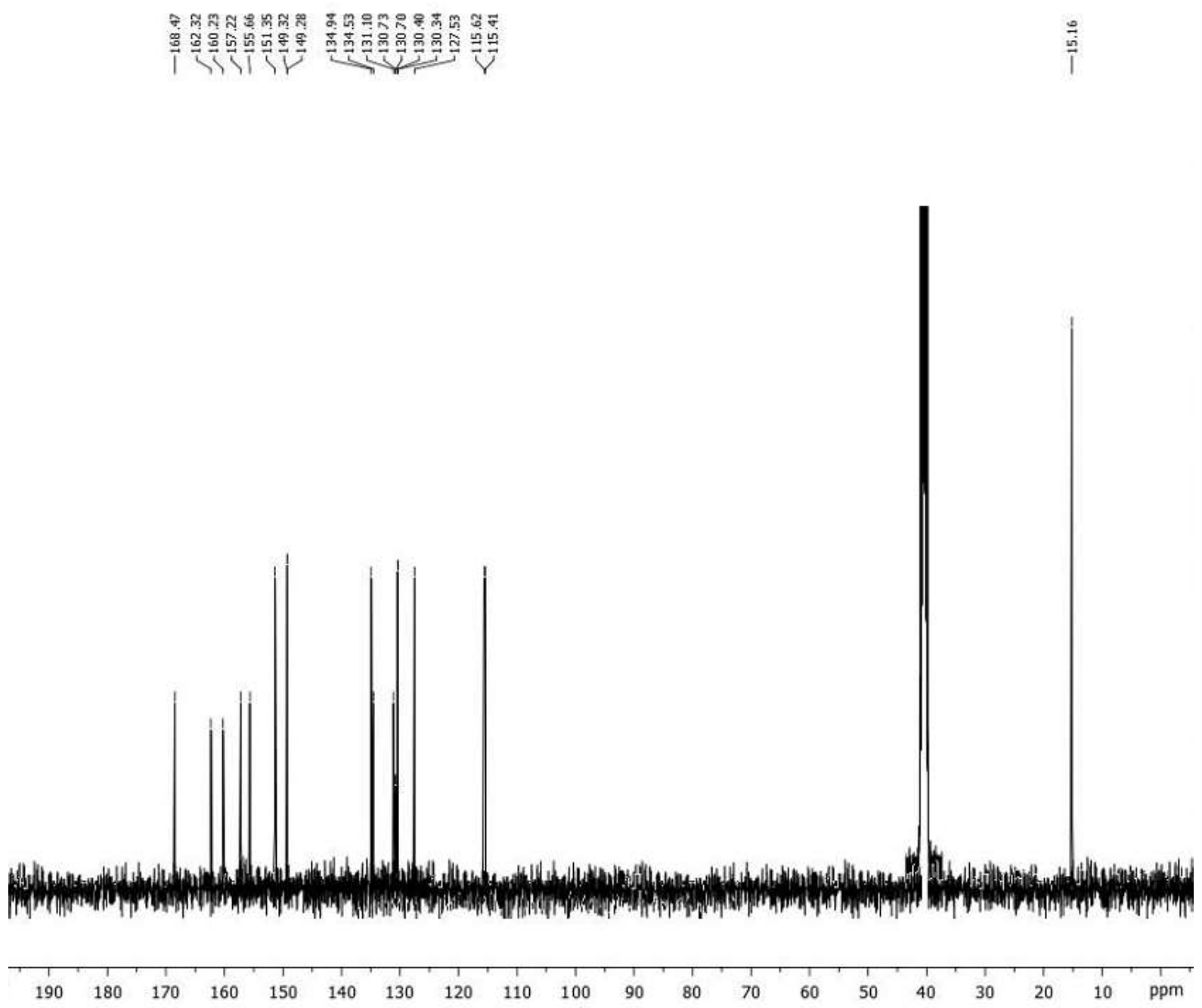

Figure S6. ${ }^{1} C$ NMR spectrum of $N^{\prime}$-(4-chlorobenzylidene)-5-methyl-2-(pyridin-3yl)thiazole-4-carbohydrazide (5a). 


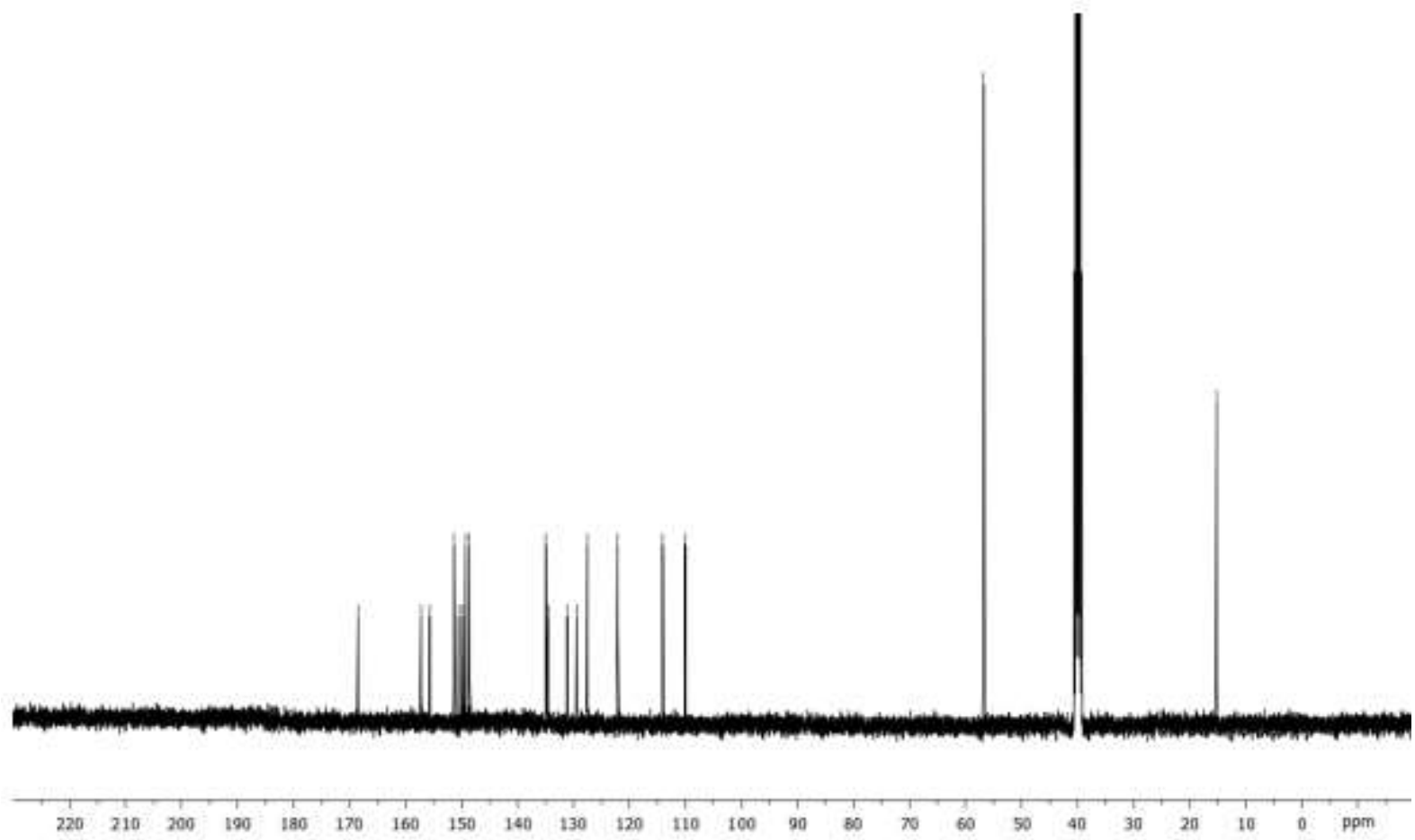

Figure S7. ${ }^{1} C$ NMR spectrum of $N^{\prime}$-(3,4-dimethoxybenzylidene)-5-methyl-2-(pyridin-3yl)thiazole-4-carbohydrazide (5b). 
1.4. ES-MS spectra of compounds $5 \mathrm{~b}, 5 \mathrm{~d}$ and $5 \mathrm{~h}$

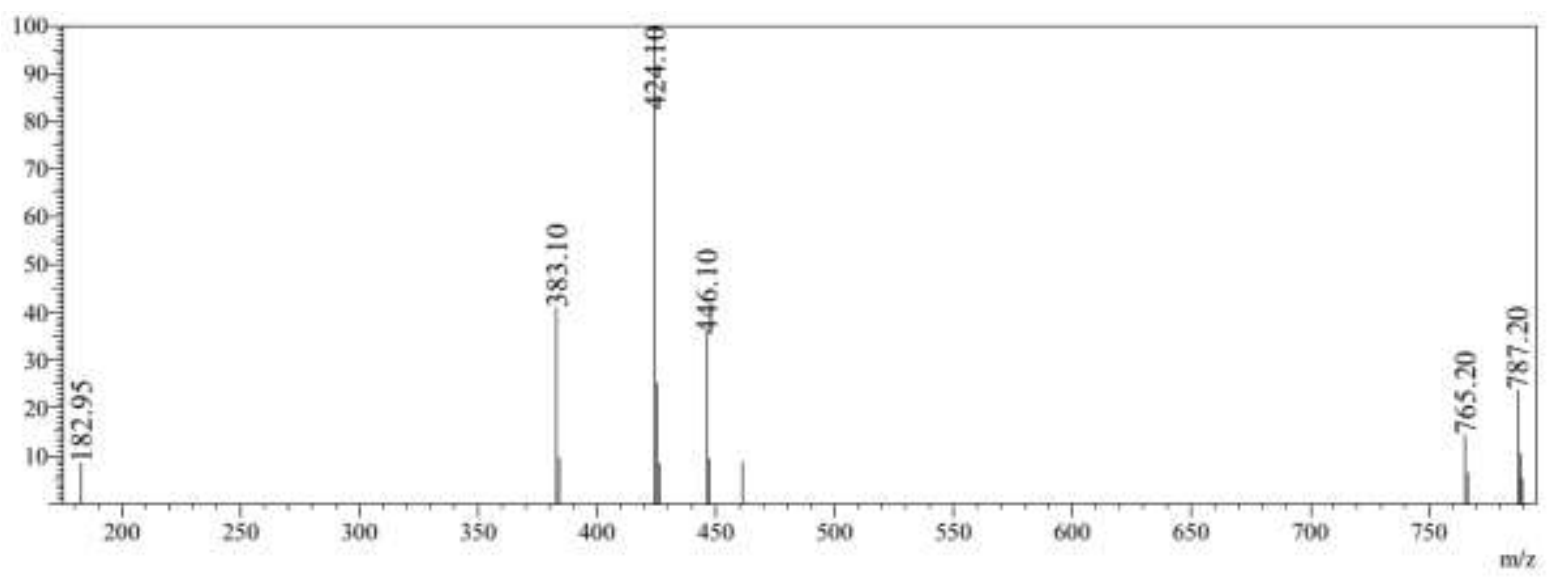

Figure S8. ES-Mass spectrum of $N^{\prime}$-(3,4-dimethoxybenzylidene)-5-methyl-2-(pyridin-3yl)thiazole-4-carbohydrazide (5b).

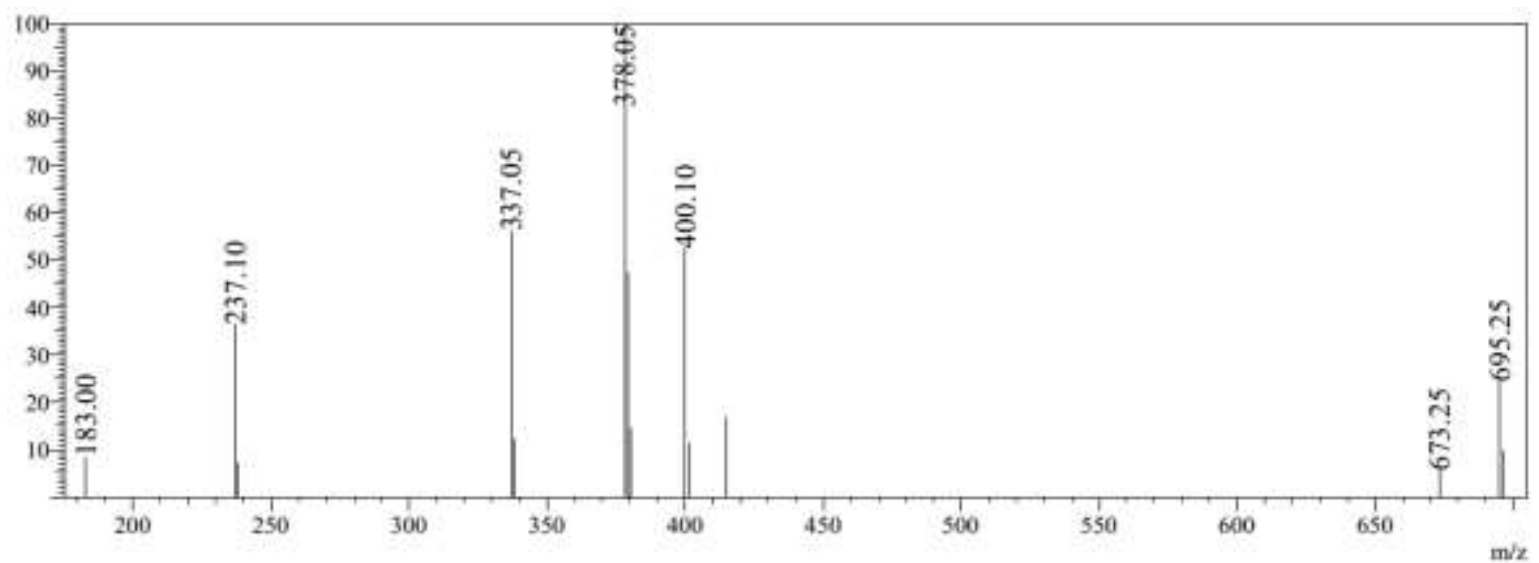

Figure S9. ES-Mass spectrum of 5-Methyl- $N^{\prime}$-(4-methylbenzylidene)-2-(pyridin-3yl)thiazole-4-carbohydrazide (5d).

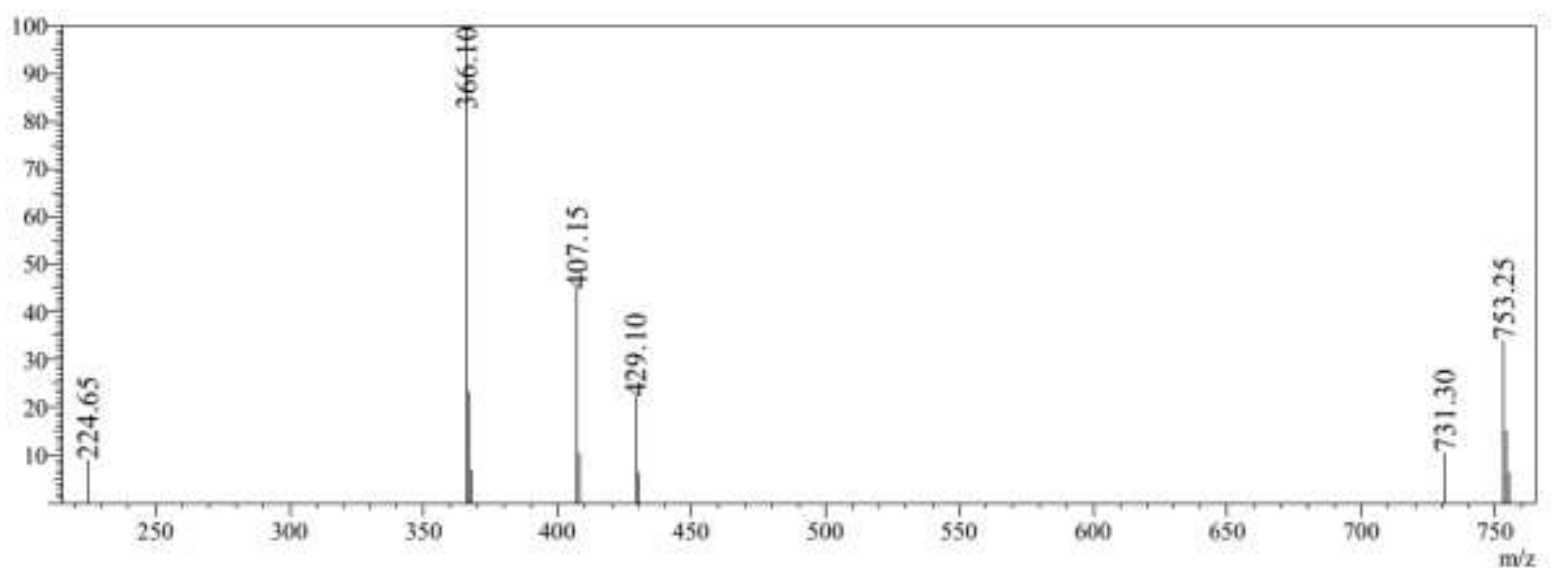

Figure S10. ES-Mass spectrum of $N^{\prime}$-(4-dimethylaminobenzylidene)-5-methyl-2-(pyridine3-yl)thiazole-4-carbohydrazide (5h). 


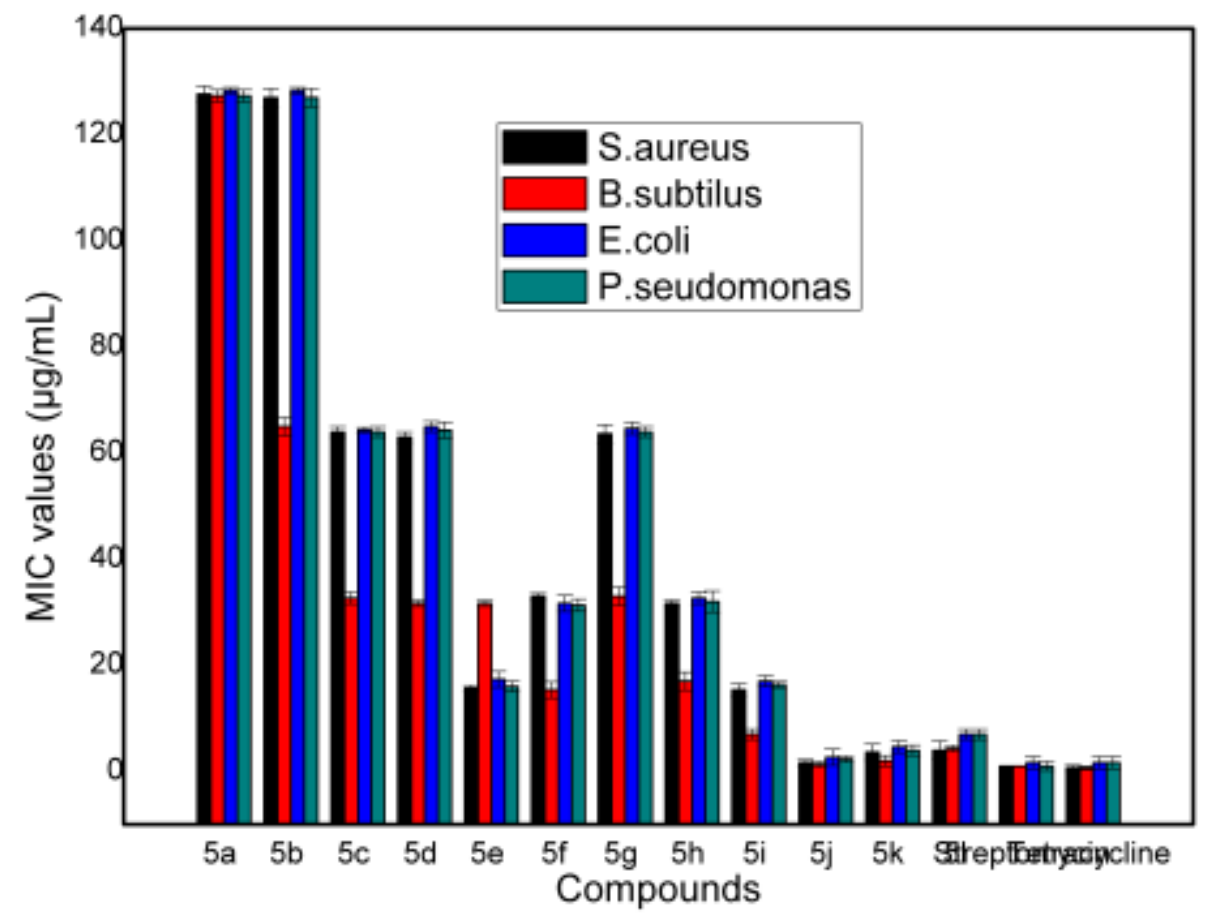

Figure S11: Graphical representation of results of the anti-bacterial evaluation of the compounds 


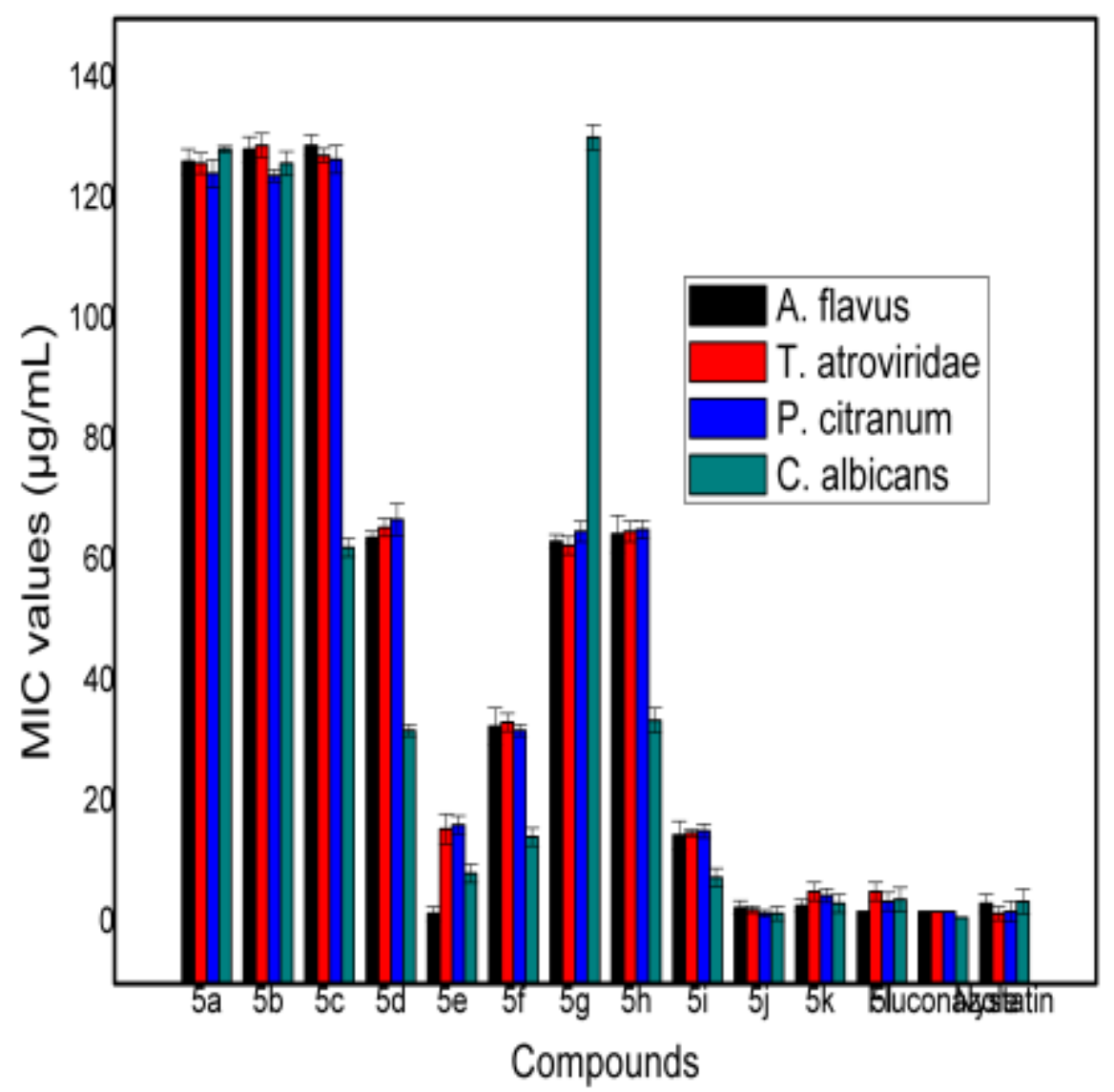

Figure S12: Graphical representation of results of the antifungal evaluation of the compounds 